SIGNIFICANCE OF FORECAST PRECISION:

THE IMPORTANCE OF EX-ANTE EXPECTATIONS

\author{
A Dissertation \\ Presented to the Faculty of the Graduate School \\ of Cornell University \\ in Partial Fulfillment of the Requirements for the Degree of \\ Doctor of Philosophy
}

by

Katarzyna Karolina Rupar

January 2011 
C 2011 Katarzyna Karolina Rupar 


\title{
SIGNIFICANCE OF FORECAST PRECISION: THE IMPORTANCE OF EX-ANTE EXPECTATIONS
}

\author{
Katarzyna Karolina Rupar, Ph. D.
}

Cornell University 2011

\begin{abstract}
I investigate whether the precision of an earnings forecast interacts with environmental uncertainty to affect investors' perceptions of management credibility, future firm growth, and firm stock price. I find that investors respond to a misalignment between environmental uncertainty and forecast precision by lowering their growth expectations and stock price estimates (lowering growth expectations and penalizing price estimates when point forecasts are issued in relatively uncertain environments or range forecasts are issued in relatively certain environments). I find a similar pattern of results for investors' perceptions of management credibility. Perceptions of management credibility mediate the impact of misalignment on investors' perceptions of future growth but do not mediate the impact of misalignment on stock price estimates. My findings have implications for managers issuing forecasts and for investors interpreting forecasts.
\end{abstract}




\section{BIOGRAPHICAL SKETCH}

Kathy will receive her $\mathrm{PhD}$ from Cornell University's Johnson Graduate School of Management, obtained bachelors and masters of accounting degrees from the University of Illinois at Urbana-Champaign, and received a CPA certification from the state of Illinois. Prior to joining the academic world, she spent a short period of time in the audit industry.

As of August 2010, Kathy is an Assistant Professor at the University of Florida's Fisher School of Accounting. She teaches in the area of financial reporting. On the research front, her curiosity of human behavior has led her to investigate the unexpected ways in which market participants interpret different formats and disclosures of financial information. Some of her current projects look into how the combination of what investors expect and managers disclose affects firm stock price, how investors make risk judgments, and why some analysts can be more accurate yet more biased in their forecasts at the same time.

Outside of the office, Kathy works on improving her tennis game, enjoys biking and keeping active, and adores the company of her two rambunctious felines. 
To all without whom this would not be possible:

\section{MY PARENTS}

for giving up their homeland to provide me with better opportunities

\section{MARK}

for incredible patience, invaluable guidance, and inspiration to 'ponder it'

SEAN

for endless support and ability to lift my spirits every single time (and there have been many) 


\section{ACKNOWLEDGMENTS}

I thank my dissertation committee members Mark Nelson (Chair), Robert Libby, Dennis Regan, and Steven Schwager for their valuable guidance and advice. This paper has also benefited from comments provided by workshop participants at Cornell University, Florida State University, Iowa State University, and the Universities of Alberta, Florida, Illinois at Urbana-Champaign, Massachusetts Amherst, South Carolina, and South Florida, as well as by Robert Bloomfield, Shana Clor-Proell, Kristina Rennenkamp, Nick Seybert, and Sean Wang. 


\section{TABLE OF CONTENTS}

BIOGRAPHICAL SKETCH iii

DEDICATION

ACKNOWLEDGMENTS $\quad \mathrm{V}$

TABLE OF CONTENTS vi

LIST OF FIGURES vii

LIST OF TABLES viii

CHAPTER 1 INTRODUCTION 1

CHAPTER 2 BACKGROUND AND HYPOTHESES 6

Forecast Precision $\quad 6$

Attribution Theory and Management Credibility 9

$\begin{array}{lr}\text { Signaling as an Alternative Hypothesis } & 10\end{array}$

Firm Valuation 11

Confidence in Firm Valuation $\quad 14$

CHAPTER 3 EXPERMIENT 15

Design 15

$\begin{array}{ll}\text { Participants } & 15\end{array}$

$\begin{array}{lr}\text { Procedure } & 16\end{array}$

Dependent Variables 18

CHAPTER 4 RESULTS 20

Comprehension Checks 20

Descriptive Statistics $\quad 20$

Effects of Misalignment - Credibility 26

Effects of Misalignment - Growth 27

Effects of Misalignment - Stock Price Estimates 30

Effects of Misalignment - Mediation Analyses 32

Effects of Misalignment - Signaling Hypothesis 37

Confidence in EPS Estimates 38

$\begin{array}{lll}\text { CHAPTER } 5 \text { CONCLUSION } & 40\end{array}$

$\begin{array}{lll}\text { APPENDIX PILOT EXPERIMENT } & 44\end{array}$

Hypotheses $\quad 44$

Design 47

Results $\quad 47$

Adjustments Made Prior to Primary Experiment 48

BIBLIOGRAPHY 50 


\section{LIST OF FIGURES}

FIGURE 1: H1-H3 Causal Model 12

FIGURE 2: Experimental Design 15

FIGURE 3: Overall Results 33 


\section{LIST OF TABLES}

TABLE 1: Credibility Descriptive Statistics $\quad 21$

TABLE 2: Growth Descriptive Statistics 23

TABLE 3: Stock Price Descriptive Statistics $\quad 24$

TABLE 4: Test of H1 28

TABLE 5: Test of H2 29

TABLE 6: Test of H3 31

TABLE 7: Test of Mediation for Credibility Perceptions 35

TABLE 8: Test of Mediation for Growth Expectations 36

TABLE 9: Test of H4 39 


\section{CHAPTER 1}

\section{INTRODUCTION}

I investigate the impact of voluntary positive performance forecasts on investors' judgments of management credibility, future firm growth, and firm stock price. Faced with investor skepticism, managers issuing positive earnings forecasts have a difficult task of credibly relaying information contained in these voluntary disclosures. Prior research has investigated how management choices regarding the characteristics of positive performance forecasts may improve investors' assessments of management credibility. For example, Hirst, Koonce, and Venkataraman (2007) find that management's choice to disaggregate positive earnings forecasts leads to increased perceptions of credibility, which in turn impact investors' estimates of a firm's price earnings multiple. Yet, little evidence exists that managements' decision regarding another forecast characteristic, forecast precision, has a similar impact on investors' immediate judgment (Hirst, Koonce, Miller 1999). I contribute to this area of accounting literature by introducing investors' ex-ante expectations as a variable that determines the impact of forecast precision on investors' judgments. Specifically, I focus on the inferences that investors make prior to learning the realization of the forecast and predict lower management credibility perceptions, lower future growth expectations, and lower stock price estimates when the actual precision of the forecast does not align with investors' expectations than when it does align.

Although not mandatory, issuances of management earnings forecasts have been prominent in recent years. Cotter, Tuna, and Wysocki (2006) document that $31 \%$ of firms captured by the First Call database disclosed management forecasts in 
2001, versus the $11 \%$ of firms that issued them in $1995 .^{1}$ Prior research also finds that management's earnings forecasts are informative to the market, as analysts and investors rely on this information when making investment recommendations (Cotter, Tuna, Wysocki 2006) and investment decisions (e.g. Rogers and Stocken 2005).

Libby, Tan, and Hunton (2006) (hereafter LTH) provide experimental evidence that forecast precision does not affect analysts' earnings per share (EPS) estimates following disclosure of an earnings forecast, but does affect analysts' EPS estimates following the actual earnings announcement. LTH explain these results as driven by the combined knowledge of forecast precision and forecast error. Since information about forecast error is only available following the actual earnings announcement, only at that time can analysts assess whether managements' forecast precision was appropriate. I predict that, when investors have ex-ante expectations about the amount of uncertainty within a firm's forecasting environment, forecast precision can affect investors' decisions even before the earnings announcement.

In addition to testing the effects of forecast precision on growth expectations and stock price estimates, I investigate how investors reach these estimates. Based on attribution theory (Gilbert and Malone 1995), I predict that when forecast precision does not align with expected environmental uncertainty, investors question that inconsistency and attribute its cause to management characteristics such as competence and trustworthiness. Further, because management discloses positive news, initial investor skepticism leads to attributions that are negative, lowering perceptions of management credibility, which in turn impact investors' expectations of future growth and stock price estimates.

\footnotetext{
${ }^{1}$ Further, of the 515 National Investor Relations Institute (NIRI) members who responded to the annual forward-looking guidance practices survey, 60\% indicated that they issued earnings guidance in 2009 (www.NIRI.org).
} 
To test my predictions, I implement a $2 \times 2$ between subjects factorial design in which I manipulate the precision of a positive news forecast (point forecast vs. range forecast) and investors' expectations about the uncertainty present in the firm's environment (high uncertainty vs. low uncertainty). Participants make an initial stock price estimate, then view a management earnings forecast, and then reevaluate their initial stock price estimate. Next they state how confident they feel about their final stock price estimate, answer questions about management credibility, and indicate their future growth expectations. I set my study within the context of a firm disclosing positive news because prior research has documented that positive news disclosures face particular credibility challenges (Williams 1996, Mercer 2005, Rogers and Stocken 2005). Since disclosing favorable information is typically in line with selfserving incentives, market participants are especially skeptical of these types of disclosures. I manipulate expectations of environmental uncertainty by providing information about environmental uncertainty and the level of analyst consensus regarding earnings forecasts (uncertain environment with low analyst consensus vs. certain environment with high analyst consensus).

Testing my predictions using an experiment provides several advantages for this study. An experimental approach allows me to hold constant characteristics of the company and voluntary disclosure that might covary with forecast precision in practice. Also, via experimental treatments, I can obtain an adequate sample size of combinations of forecast precision and environmental uncertainty that are underrepresented in practice but that shed light on the theoretical constructs I am investigating. Finally, with an experiment I can elicit intervening variables (i.e., perceptions of management competence and trustworthiness) that allow me to test my process theory for the effect of forecast precision on growth expectations and stock price estimates. 
My findings confirm that misalignment between forecast precision and investors' expectations regarding environmental uncertainty decreases investors' perceptions of management credibility, their growth expectations, and their stock price estimates. However, while perceptions of management credibility serve as a mediator between misalignment and growth expectations, they do not serve as a mediator between misalignment and stock price estimates. This result suggests that misalignment between environmental uncertainty and forecast precision leads investors to draw inferences regarding more than just management credibility when generating their stock price estimates.

This research contributes to the current literature in several respects. First, I identify one reason that may explain why prior behavioral studies have not documented an effect of forecast precision immediately following an earnings forecast. Since prior studies were designed to focus on characteristics of the forecast and not investors' expectations about forecast precision, prior research has not examined how the cues provided by forecast precision interact with pre-existing investors' expectations. I provide the first evidence that pre-existing expectations interact with forecast precision to affect growth expectations and stock price estimates. Second, by documenting an effect of forecast precision immediately after earnings guidance, I highlight the significance of this formatting choice to management and suggest that further investigation of the effects of forecast precision are warranted. For example, format expectations may also affect how forecast precision and forecast error interact following earnings announcements in addition to following earnings forecasts. Third, I aid managers in more effectively anticipating concerns about management credibility by providing evidence about how a choice of forecast precision affects management credibility at different levels of environmental uncertainty. 
The remainder of this paper is organized as follows. In Chapter 2, I discuss background literature and develop my hypotheses. I describe my experimental design in Chapter 3. I present results in Chapter 4 and conclude with Chapter 5. 


\section{CHAPTER 2}

\section{BACKGROUND AND HYPOTHESES}

\section{Forecast Precision}

In a framework based on Ajinkya and Gift's (1984) expectations adjustment hypothesis, King, Pownall, and Waymire (1990) propose that the value relevance of management forecasts is based on forecast timing, credibility, and form (or precision). Baginski and Hassell (1990) show that forecast timing is important when comparing fourth quarter versus non-fourth quarter forecasts, since fourth quarter disclosures are more closely followed by analysts. Prior research also finds that various characteristics of forecasts such as news valence (Williams 1996, Hutton, Miller, and Skinner 2003, Mercer 2005, Rogers and Stocken 2005), forecast disaggregation (Hirst, Koonce, and Venkataraman 2007), forecast accuracy (Williams 1996, Hirst, Koonce, and Miller 1999) and supplementary forecast information (Hutton, Miller, and Skinner 2003, Barton and Mercer 2005) all impact investors' behavior via their effect on perceptions of management credibility.

Yet, few studies document an effect of forecast precision (e.g. point vs. range estimates) on reactions to earnings forecasts, and those that do, provide conflicting evidence. Archivally, Baginski, Conrad, and Hassell (1993) and Baginski, Hassell, and Wieland (2007) find a significant relationship between returns and forecast precision immediately following guidance, but Pownall, Wasley, and Waymire (1993)

and Atiase, Li, Supattarakul and Tse (2005) do not. Experimentally, neither Hirst, Koonce, and Miller (1999) nor Libby, Tan, and Hunton (2006) find that forecast precision has an impact on investors' own forecasts of firm performance following 
forecast issuance. ${ }^{2}$ Han and Tan (2010) find a marginally significant effect of forecast precision immediately following forecast issuance, but only when investors have directional preferences in a positive news forecast setting. That is, they find that participants assigned a long (short) position are more likely to provide a higher (lower) earnings estimate given a positive news range forecast than given a positive news point forecast. Han and Tan explain that viewing a range forecast allows motivated reasoning (i.e. long/short investors' preferences for good/poor performance) to affect investors' judgments more freely (given greater uncertainty in future firm performance) than viewing a point forecast. However, this result is in disagreement with archival findings in Baginski et al. (2007) which suggest that more precise (e.g. point) forecasts rather than less precise (e.g. range) forecasts lead to greater price and analyst guidance revision. Further, consistent with prior experimental studies, Han and Tan find no effect of forecast precision in control treatments in which participants have no directional preferences (as is the case in my study).

Libby, Tan, and Hunton (2006) (hereafter LTH) suggest that the reason for the lack of prior findings regarding the impact of forecast precision stems from focusing on too narrow of a time frame. LTH argue that the effect of forecast precision can only be fully understood following the actual earnings announcement, when analysts can interpret information inherent in the precision of the forecast along with the forecast error. Their results indicate that, once an earnings forecast is realized, analysts' own forecasts respond to the direction of forecast error differently depending on whether the forecast was a point estimate, a narrow range estimate, or a wide range estimate. It appears that evaluating forecast form along with forecast error allows analysts to draw inferences about the level of uncertainty surrounding the forecast

\footnotetext{
${ }^{2}$ Both Hirst et al. (1999) and Libby et al. (2006), however, find that forecast precision affects investors' confidence in their own forecasts immediately following guidance.
} 
estimate (i.e., inferring more uncertainty when the forecast is a wide-range estimate and less when the forecast is a point estimate) and about how well management responded to that uncertainty (i.e., management over- or under-estimating actual earnings performance).

However, what if investors already have pre-established expectations regarding the amount of uncertainty within the environment, and those expectations do not align with management beliefs? Most firms do not follow a set policy regarding the precision of forecast they issue (Bamber and Cheon 1998; Hirst, Koonce, and Miller 1999), suggesting that forecast precision could vary with environmental factors and be seen as a signal of precision of management information.

The consensus, or lack thereof, among analysts may be one salient cue regarding the amount of uncertainty surrounding information about firm performance. Consistent with descriptive statistics in Baginski, Conrad, and Hassell (1993), an untabulated analysis of the frequency of Point and Range earnings forecasts given high and low analyst consensus for forecasts issued between 1994 and 2006 suggests that all four combinations of Point/Range forecast and Low/High environmental uncertainty occur in the market. ${ }^{3}$ Investors' expectations do not always align with management perceptions of environmental uncertainty. ${ }^{4}$

Given the existence of settings in which firms disclose earnings forecasts with precision that does and does not align with investors' expectations, I turn to expectations-related psychology literature to consider the effects of misalignment on

\footnotetext{
${ }^{3}$ Point and Range estimates constitute a significant portion of earnings forecasts issued. Between 1994 and 2006 approximately $20 \%$ (65\%) of all forecasts issued were point (range) estimates. Remaining forecasts take the form of minimum, maximum, or qualitative predictions (Source: First Call Company Issue Guidelines).

${ }^{4}$ In this study I use analyst consensus as an example of a cue regarding a firm's environmental uncertainty. However, investors may also look to various other environmental uncertainty cues, for example, industry membership (Hrebiniak and Snow 1980) or stage in the firm's life cycle (Mueller 1972).
} 
investors' judgments.

\section{Attribution Theory and Management Credibility}

Attribution theory suggests that unexpected forecast precision can affect market reactions to an earnings forecast, particularly through its impact on perceptions of management credibility. Attribution theory concerns inferences people make in order to discern what causes various observed behaviors (Fiske and Taylor 1991). It posits that decision makers tend to possess ex ante expectations about an observed behavior, and that when reality does not align with expectations, observers are prone to attribute the behavior to internal rather than external characteristics (Gilbert and Malone 1995). Therefore, when forecast precision and environmental uncertainty expectations do not align, rather than assume the misalignment was caused by one of various external factors, investors are more likely to question management credibility. Further, in cases where investors are already skeptical of management motivation for disclosing an earnings forecast, such as when management discloses positive news forecasts, attributions to management credibility are likely to be negative. As a result, attribution theory suggests that, given a positive news forecast, perceptions of management credibility will be significantly lower when environmental uncertainty and forecast precision do not align than when they align. ${ }^{5}$

\footnotetext{
${ }^{5}$ Most prior accounting studies that take investor expectations into account do not investigate whether or not expectations align with what the market observes in reality. Clor-Proell (2009) is one exception. She manipulates investor expectations about how a firm will report stock option compensation by varying whether other firms in the industry recognize stock option expense in the financial statements or only disclose stock option expense in the footnotes. She shows that, when a firm chooses a format that does not align with investor expectations but is more/less preferred by the market (as is the case with recognition/disclosure of stock option expense), investor reactions are more extreme (in both positive and negative signal cases) than when a firm chooses a format that aligns with investor expectations. Whereas Clor-Proell investigated effects of disclosure location (recognized vs. disclosed), I investigate effect of forecast precision (point vs. range). Further, it is not clear that disclosing a less precise (range) estimate instead of a more precise (point) estimate is perceived as a strong negative signal akin to disclosing stock option compensation in the footnotes. Psychology studies provide evidence that decision makers generally prefer more precise (numeric) information (Kuhn and Budescu 1996; Kuhn, Budescu, Hershey, Kramer, and Rantilla 1999), but other research
} 
H1: Perceptions of management credibility are lower when expectations about environmental uncertainty and precision of positive news forecasts do not align than when they align.

\section{Signaling as an Alternative Hypothesis}

Signaling theory concerns why, given an asymmetric information environment, certain types of communication are considered more reliable than others. It suggests that a manager's signal is viewed as more reliable if the cost of falsely issuing that signal is higher than the benefit (Spence 1974). Because the market punishes firms that do not meet their earnings forecasts with lower stock prices, and missing a point forecast is more likely than missing a range forecast, issuing a positive point forecast in a highly uncertain environment could be perceived as a more reliable signal of positive private information.

Thus, contrary to attribution theory, signaling theory would predict that participants will assign high management credibility ratings in the misalignment scenario where a point forecast is issued given a highly uncertain environment. Therefore, for $\mathrm{H} 1$ to hold in the Point Forecast/High Uncertainty setting, the negative attribution associated with misalignment must exceed any positive signal that investors perceive.

In the study, I address the potential presence of signaling expectations in two ways: by using a design in which signaling cannot explain my predicted pattern of results, and by debriefing questions that elicit investors' considerations that management may possess positive private information.

suggests that preference for more precise vs. less precise information may depend on the type of event being predicted (Zimmer 1983, Wallsten, Budescu, Zwick, and Kemp 1993, Windschitl and Wells 1996, and Olson and Budescu 1997). In some circumstances receiving information that is too precise may be perceived just as negatively as receiving information that is not precise enough. My experiment allows me to investigate both of these cases. 


\section{Firm Valuation}

Perceptions of management credibility have been linked to various economically significant investor and analyst behaviors. For example, studies have shown that perceptions of management credibility affect investors' willingness to rely on subsequent management disclosures (Mercer 2005), estimates of firm priceearnings (P/E) multiples (Barton and Mercer 2005; Hirst, Koonce, and Venkataraman 2007), and investment decisions (Clor-Proell 2009). The main measure of investor and analyst behavior in forecast precision studies, however, has been an EPS estimate. To link these two streams of literature I investigate the effect of credibility on both a P/E multiple related measure (i.e. growth) and on stock price estimates, which incorporate information from the P/E multiple measure used in credibility studies and the EPS measure used in forecast precision studies. I depict these relationships with a causal model in Figure 1 and refer to each link of the model as I describe H2 and H3. Note that the already discussed $\mathrm{H} 1$ is depicted with Link 1 in the model and identifies the relationship between misalignment (of environmental uncertainty and forecast precision) and investor perceptions of management credibility.

Prior research has already established a relationship between perceptions of management credibility and growth-related measures presented via Link 2 in Figure 1 (Barton and Mercer 2005, Hirst, Koonce, Venkataraman 2007). I therefore predict that misalignment will have a similar effect on growth as it does on management credibility (Figure 1: Link 3):

H2: Perceptions of future growth are lower when expectations about environmental uncertainty and precision of positive news forecasts do not align than when they align. 


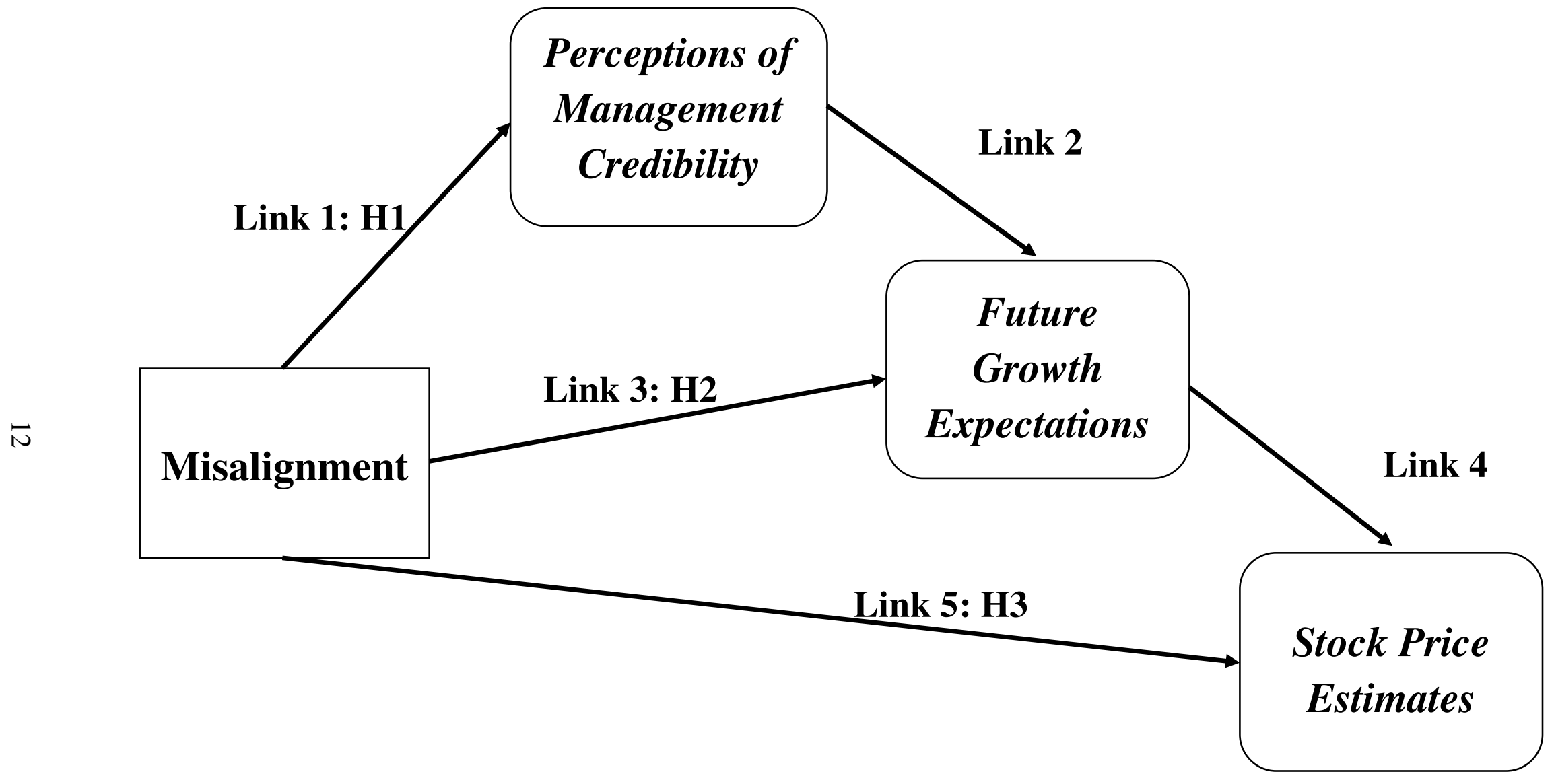

FIGURE 1: H1-H3 Causal Model

Figure 1 presents a causal model that depicts the relationships among the first three hypotheses (i.e. H1-H3). 
Since growth perceptions are a component of stock price estimates (Figure 1: Link 4), I predict that stock price estimates will also follow the same pattern as do perceptions of management credibility, being less favorable when environmental uncertainty and forecast precision do not align than when they align (Figure 1: Link $5)$.

H3: Stock price estimates are lower when expectations about environmental uncertainty and precision of positive news forecasts do not align than when they align.

Implied in $\mathrm{H} 1$ through $\mathrm{H} 3$, and shown in Figure 1, is a process by which perceptions of management credibility serve as a mediator between misalignment and growth expectations and as a mediator between misalignment and stock price estimates. Further, growth expectations serve as a mediator between misalignment and stock price estimates. I test each of these mediation paths in addition to my hypotheses.

Note that Environmental Uncertainty has the potential to affect growth - a major component of the $\mathrm{P} / \mathrm{E}$ multiple estimate - independent of the predicted misalignment effect. Specifically, the environmental uncertainty a firm faces may serve as a clue toward its future growth possibilities. For example, many startup companies with a high potential for growth also face high uncertainty in their operating environments (Zhang 2006, Jiang, Lee, Zhang 2005). This link between growth and uncertainty would suggest that investors' perceptions of growth may be higher given a high uncertainty environment than given a low uncertainty environment. A potential main effect of uncertainty, however, does not preclude the effect of misalignment between forecast precision and environmental uncertainty on investors' perceptions of growth or on their stock price estimates. 


\section{Confidence in Firm Valuation}

Prior research indicates that forecast precision increases investors' confidence in their estimates of future firm performance (Hirst et al. 1999; LTH). I predict that expectations about environmental uncertainty also will affect investors' confidence in valuation estimates. Since an expectation of high environmental uncertainty suggests difficulty in estimating future stock price, an investor who expects high uncertainty and views a range forecast should be least confident about his valuation estimate. On the other hand, since an expectation of low environmental uncertainty suggests ease in estimating future stock price, an investor who expects low environmental uncertainty and views a point forecast should be most confident about his valuation estimate.

H4: Investors' confidence in their stock price estimates is highest (lowest) in response to point (range) earnings forecasts evaluated with an expectation of low (high) environmental uncertainty. 


\section{CHAPTER 3}

EXPERMIENT $^{6}$

\section{Design}

I use a $2 \times 2$ between subjects design in which I manipulate forecast precision (point vs. range) and the level of uncertainty in the environment (low vs. high). ${ }^{7}$ The Low Uncertainty/Range Forecast and High Uncertainty/Point Forecast treatments represent environments of misalignment between market expectations and actual forecast precision. This design is pictured in Figure 2.

\begin{tabular}{|l|c|c|}
\hline & Low Uncertainty & High Uncertainty \\
\hline Precise (Point) Forecast & $(1)$ & $(2)$ \\
& Benchmark & Misalignment \\
\hline $\begin{array}{lc}\text { Imprecise (Range) } \\
\text { Forecast }\end{array}$ & $\begin{array}{c}(3) \\
\text { Misalignment }\end{array}$ & Benchmark \\
\hline
\end{tabular}

FIGURE 2: Experimental Design

\section{Participants}

990 alumni from a major northeastern university with finance-oriented careers are contacted via e-mail to participate in the online study. 140 alumni (24\% female)

\footnotetext{
${ }^{6}$ Details of a pilot experiment are included in the Appendix.

${ }^{7}$ Theoretically, because support for my hypotheses depends on participants understanding that earnings forecasts occur at various precision levels and firms operate in different uncertainty environments, either or both of my independent variables could have been presented within subjects. However, pilot testing suggested that asking participants to provide estimates for two different scenarios (e.g. point vs. range) established the first estimate as a benchmark which participants then use as information in determining their second estimate. Therefore, to assure that only precision and uncertainty had an effect on participant responses, I manipulate each variable between participants.
} 
complete the study, yielding a response rate of $14 \% .^{8}$ Due to an initial software problem and several participants providing EPS rather than stock price estimates, 20 responses are excluded from analysis, for a total of 120 useable responses. The average participant age is 44 . Participants have completed an average of 3 accounting and 4 finance courses, and have average working experience of 21 years, so they possess the base level of investor knowledge necessary for my experimental task. ${ }^{9}$

\section{Procedure}

All participants receive an e-mail inviting them to participate in an accounting research study which they can access on-line via a provided link. In return for participation, all participants are entered into a raffle for a new iPod touch or Nintendo Wii system and provided the option to receive a summary of the study's results following data collection and analysis. The on-line materials are designed using Qualtrics software which randomly assigns each participant to one treatment of my design and prevents participants from changing their responses throughout the duration of the study once each answer has been submitted. ${ }^{10}$

\footnotetext{
${ }^{8}$ This response rate is comparable to the response rates of other research using samples of finance and accounting professionals, e.g. Graham, Harvey, and Rajgopal's (2005) response rate of $10.4 \%$ and ClorProell and Maines' (2009) response rate of $13 \%$.

${ }^{9}$ To further assess experience with estimating firm stock price, I also ask participants to specify whether or not they possess any stock price estimate experience and if so, whether that experience comes from personal investments, professional training, or both. Participant answers to this question are included as a covariate when testing each hypothesis in order to further reduce potential noise in dependent variable responses.

${ }^{10}$ Once each participant accesses the survey, signs a consent form, and views initial study information that remains constant across all four treatments, Qualtrics randomly displays materials relevant to one of the four treatments of my design using the Mersenne Twister (MT) random number generator. Four different sets of such materials have been preprogrammed into Qualtrics, each relating to a different cell of my design, allowing the software to randomly select one set of materials per participant. This randomization procedure has one constraint - that each treatment be displayed no more than 30 times (for a total of 120 observations). Active monitoring of the data collection process suggests that Qualtrics correctly performed the randomization procedure.
} 
After signing a consent form and reading general instructions, all participants view a brief description of the target firm, Zetha Inc. ${ }^{11}$ To assure that all participants have equivalent beliefs about management's tendency to undershoot actual earnings in its forecasts, I include the following statement: "Firms that issue earnings forecasts within the electronic industry receive higher valuations when they are able to meet or beat their own forecasts than when they fail to achieve their own forecasts." Following the review of background information, all participants answer a comprehension check question to determine if they understand that Zetha Inc.'s management aims to meet or beat its earnings forecasts. Next, all participants view Zetha's income statement for the previous three years, Zetha's stock price for the year ending 2009, and the mean and median analyst earnings forecast as of September $30^{\text {th }}$, 2010. After reviewing this information, participants are asked to provide an initial estimate of stock price per share for Zetha Inc. as of December $31^{\text {st }}, 2010$.

Participants in the Low (High) Uncertainty treatments are then informed that the firm operates in a highly certain (uncertain) environment. The low (high) level of environmental uncertainty is first stated (i.e. "Overall, Zetha Inc. operates in a highly certain (uncertain) environment.") and then supported by the following statement regarding analysts' consensus: "There is strong agreement (disagreement) among analysts in their EPS forecasts." All participants are also reminded that the most recent mean and median analyst EPS forecast is $\$ 0.60$.

Next, all participants receive a management earnings forecast, where some view a point forecast and others view a range forecast:

On October 1, 2010, Zetha's management issued the following statement:

The company expects earnings per share for the year ending December 31,2010 to be above expectations due to stronger than expected sales.

\footnotetext{
${ }^{11}$ Background firm information is adapted from Libby, Tan, and Hunton (2006).
} 
Earnings per share are estimated to be approximately $\$ 0.69$ [in the range of $\$ 0.64$ to $\$ 0.74$ ] for the year.

Following the earnings forecast, I ask two more comprehension questions to assess whether participants understood the level of uncertainty and forecast form presented to them. The two questions ask that participants select which levels of environmental uncertainty (Highly Certain or Highly Uncertain) and forecast precision (Point vs. Range) apply to Zetha Inc. Each incorrect response is followed by a reiteration of the correct information. Next, all participants once again estimate the firm's stock price per share as of December $31^{\text {st }}, 2010$, specify how confident they are in this estimate, and evaluate management trustworthiness and competence. Before answering demographic questions, participants are also asked how much they believe Zetha's earnings will grow in the future, and whether or not they considered that management may possess positive private information or the potential for earnings management prior to making their stock price estimates. If participants answer 'Yes' to either of the private information or earnings management questions, they are also asked to indicate how important that information was to their stock price estimate (i.e. Not very important, Somewhat important, Very important). Finally, all participants answer several demographic questions.

\section{Dependent Variables}

Participants respond to four questions that serve as my dependent variables: a stock price estimate (the only variable elicited before and after study manipulations), a measure of confidence in the stock price estimate, a management credibility scale, and a future earnings growth expectation. For the stock price estimate, participants are asked to provide a prediction for the year ended December $31^{\text {st }}, 2010$. Next, all

participants rate how confident they are that their price per share estimates are 
accurate using an 11-point scale that varies (in intervals of 10) from 0 (Not at all confident) to 100 (Certain) ${ }^{12}$. The management credibility scale consists of 2 questions which ask whether management is competent and trustworthy ${ }^{13}$; each question varies with the precision and uncertainty treatment as follows: 1) "Given Zetha's highly certain [uncertain] operating environment and management's point [range] earnings forecast, I trust Zetha's management," 2) “Given Zetha's highly certain [uncertain] operating environment and management's point [range] earnings forecast, Zetha's management is competent". Participants respond on a 7 point Likert scale with endpoints 1 (Strongly Disagree) and 7 (Strongly Agree) and midpoint 4 (Neutral). For the future earnings growth expectation, participants are asked to respond on a Likert scale with endpoints 1 (Zero Growth) and 7 (High Growth) and midpoint 4 (Moderate Growth).

\footnotetext{
${ }^{12}$ The wording for the confidence DV and its scale is adapted from Hirst, Koonce, and Miller (1999) and Libby, Tan, and Hunton (2006).

${ }^{13}$ The management credibility scale is consistent with questions asked in prior accounting credibility studies (e.g. Mercer 2005; Barton and Mercer 2005; Hirst, Koonce, Venkataraman 2007) all of which rely on a widely accepted and validated source credibility scale (McCroskey 1966; Leathers 1992; Newell and Goldsmith 2001)
} 


\section{CHAPTER 4}

\section{RESULTS}

\section{Comprehension Checks}

Comprehension check questions appeared before participants responded to the post-manipulation dependent variables. Each incorrect response was followed by a reiteration of the correct information, so I include all participants in my analyses. A total of 10 participants $(8 \%)$ missed at least one comprehension check. ${ }^{14,15}$

\section{Descriptive Statistics}

Descriptive statistics (i.e., means, standard deviations, and medians) for each dependent variable are provided in Tables 1-3. In order to reduce response noise and address differences in participant experience levels in estimating firm stock price, I include an ExperienceType covariate in the test of each hypothesis (ExperienceType = None, Personal, Professional, Both Personal and Professional). Given the ExperienceType covariate and the categorical nature of my two independent variables, I use analysis of covariance (ANCOVA) to test H1 through H4.

While equality of variances is satisfied across treatments (Levene's test pvalues $\geq 0.272$ ), the Anderson-Darling test of normality rejects (at $p \geq 0.076$ ) the null that responses to each of my dependent variables are normally distributed. However,

\footnotetext{
${ }^{14}$ These participants are distributed as follows across experimental treatments: three are from the low uncertainty/point condition; four are from the low uncertainty/range condition, and three are from the high uncertainty/point condition. All participants from the high uncertainty/range condition answered all three comprehension check questions correctly.

${ }^{15}$ Excluding participants who missed at least one comprehension check question does not affect the significance of the test of $\mathrm{H} 4$, marginally reduces the significance of tests of $\mathrm{H} 1$ and $\mathrm{H} 3$ but does not affect the qualitative interpretation of the data, and leads to a non significant result for H2. Specifically, the significance of the test of $\mathrm{H} 1$ reduces from a p-value of 0.018 to a p-value of 0.067 ; the significance of the test of $\mathrm{H} 2$ reduces from a p-value of 0.095 to a p-value of 0.227 ; the significance of the test of $\mathrm{H} 3$ reduces from a p-value of 0.046 to a p-value of 0.067 .
} 
TABLE 1: Credibility Descriptive Statistics

PANEL A: Average Credibility Rating Descriptive Statistics - Mean, (Standard Deviation), [Median]

\begin{tabular}{|c|c|c|c|c|}
\hline & \multicolumn{3}{|c|}{ Environmental Uncertainty } \\
\hline & & Low & High & Overall \\
\hline \multirow{3}{*}{ } & Point & $\begin{array}{c}4.98 \\
(1.00)[5.00]\end{array}$ & $\begin{array}{c}4.08 \\
(0.83)[4.00]\end{array}$ & $\begin{array}{c}4.53 \\
(1.02)[4.50]\end{array}$ \\
\hline & Range & $\begin{array}{c}4.43 \\
(1.09)[4.00]\end{array}$ & $\begin{array}{c}4.40 \\
(0.80)[4.00]\end{array}$ & $\begin{array}{c}4.42 \\
(0.95)[4.00]\end{array}$ \\
\hline & Overall & $\begin{array}{c}4.71 \\
(1.08)[5.00]\end{array}$ & $\begin{array}{c}4.24 \\
(0.83)[4.00]\end{array}$ & \\
\hline
\end{tabular}

PANEL B: Competence Rating Descriptive Statistics - Mean, (Standard Deviation), [Median]

\begin{tabular}{|c|c|c|c|c|}
\hline & \multicolumn{3}{|c|}{ Environmental Uncertainty } \\
\hline & & Low & High & Overall \\
\hline \multirow{3}{*}{ 总 } & Point & $\begin{array}{c}4.90 \\
(1.19)[5.00]\end{array}$ & $\begin{array}{c}4.07 \\
(0.83)[4.00] \\
\end{array}$ & $\begin{array}{c}4.48 \\
(1.10)[4.00] \\
\end{array}$ \\
\hline & Range & $\begin{array}{c}4.40 \\
(1.07)[4.00]\end{array}$ & $\begin{array}{c}4.40 \\
(1.00)[4.00]\end{array}$ & $\begin{array}{c}4.40 \\
(1.03)[4.00]\end{array}$ \\
\hline & Overall & $\begin{array}{c}4.65 \\
(1.15)[4.50]\end{array}$ & $\begin{array}{c}4.24 \\
(0.93)[4.00]\end{array}$ & \\
\hline
\end{tabular}


TABLE 1: (Continued)

PANEL C: Trustworthiness Rating Descriptive Statistics - Mean, (Standard Deviation), [Median]

\begin{tabular}{|c|c|c|c|c|}
\hline & \multicolumn{3}{|c|}{ Environmental Uncertainty } \\
\hline & & Low & High & Overall \\
\hline \multirow{3}{*}{ 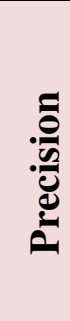 } & Point & $\begin{array}{c}5.07 \\
(1.05)[5.00]\end{array}$ & $\begin{array}{c}4.10 \\
(1.03)[4.00]\end{array}$ & $\begin{array}{c}4.59 \\
(1.14)[4.00]\end{array}$ \\
\hline & Range & $\begin{array}{c}4.47 \\
(1.22)[4.00]\end{array}$ & $\begin{array}{c}4.40 \\
(0.81)[4.00]\end{array}$ & $\begin{array}{c}4.44 \\
(1.03)[4.00]\end{array}$ \\
\hline & Overall & $\begin{array}{c}4.77 \\
(1.17)[5.00]\end{array}$ & $\begin{array}{c}4.25 \\
(0.93)[4.00]\end{array}$ & \\
\hline
\end{tabular}

Table 1 presents descriptive statistics - Mean (Standard Deviation), and [Median] for the average of management competence and trustworthiness (Panel A), investors' ratings of management competence (Panel B), and investors' ratings of management trustworthiness (Panel C). The shaded areas represent the two conditions where Environmental Uncertainty and Forecast Precision do not align (i.e. Low Environmental Uncertainty/Range Forecast, High Environmental Uncertainty/Point Forecast). 
TABLE 2: Growth Descriptive Statistics

Mean, (Standard Deviation), [Median]

\begin{tabular}{|c|c|c|c|c|}
\hline & \multicolumn{3}{|c|}{ Environmental Uncertainty } \\
\hline & & Low & High & Overall \\
\hline \multirow{3}{*}{ 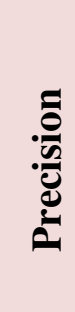 } & Point & $\begin{array}{c}4.07 \\
(0.91)[4.00]\end{array}$ & $\begin{array}{c}3.77 \\
(0.94)[4.00]\end{array}$ & $\begin{array}{c}3.92 \\
(0.93)[4.00]\end{array}$ \\
\hline & Range & $\begin{array}{c}3.70 \\
(0.92)[4.00] \\
\end{array}$ & $\begin{array}{c}4.00 \\
(0.91)[4.00] \\
\end{array}$ & $\begin{array}{c}3.85 \\
(0.92)[4.00] \\
\end{array}$ \\
\hline & Overall & $\begin{array}{c}3.88 \\
(0.92)[4.00]\end{array}$ & $\begin{array}{c}3.88 \\
(0.92)[4.00]\end{array}$ & \\
\hline
\end{tabular}

Table 2 presents descriptive statistics - Mean (Standard Deviation), and [Median] for investors' expectations of future firm growth. The shaded areas represent the two conditions where Environmental Uncertainty and Forecast Precision do not align (i.e. Low Environmental Uncertainty/Range Forecast, High Environmental Uncertainty/Point Forecast). 
TABLE 3: Stock Price Descriptive Statistics

PANEL A: Price Difference (= Post Treatment Price Estimate - Pre Treatment Price Estimate) Descriptive Statistics - Mean, (Standard Deviation), [Median]

\begin{tabular}{|c|c|c|c|c|}
\hline & \multicolumn{3}{|c|}{ Environmental Uncertainty } \\
\hline & & Low & High & Overall \\
\hline \multirow{3}{*}{ 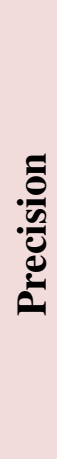 } & Point & $\begin{array}{c}0.93 \\
(0.51)[0.90]\end{array}$ & $\begin{array}{c}0.58 \\
(0.39)[0.68]\end{array}$ & $\begin{array}{c}0.76 \\
(0.48)[0.90]\end{array}$ \\
\hline & Range & $\begin{array}{c}0.72 \\
(0.54)[0.75]\end{array}$ & $\begin{array}{c}0.69 \\
(0.48)[0.80]\end{array}$ & $\begin{array}{c}0.71 \\
(0.50)[0.80]\end{array}$ \\
\hline & Overall & $\begin{array}{c}0.83 \\
(0.53)[0.90]\end{array}$ & $\begin{array}{c}0.64 \\
(0.44)[0.78]\end{array}$ & \\
\hline
\end{tabular}

PANEL B: Post Treatment Price Estimate Descriptive Statistics - Mean, (Standard Deviation), [Median]

\begin{tabular}{|c|c|c|c|c|}
\hline & \multicolumn{3}{|c|}{ Environmental Uncertainty } \\
\hline & & Low & High & Overall \\
\hline \multirow{3}{*}{ 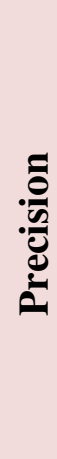 } & Point & $\begin{array}{c}6.97 \\
(0.76)[6.90]\end{array}$ & $\begin{array}{c}6.50 \\
(0.46)[6.50]\end{array}$ & $\begin{array}{c}6.73 \\
(0.67)[6.90]\end{array}$ \\
\hline & Range & $\begin{array}{c}6.73 \\
(0.69)[6.40]\end{array}$ & $\begin{array}{c}6.66 \\
(0.52)[6.80]\end{array}$ & $\begin{array}{c}6.69 \\
(0.61) \text { [6.78] }\end{array}$ \\
\hline & Overal & $\begin{array}{c}6.85 \\
(0.73)[6.90]\end{array}$ & $\begin{array}{c}6.58 \\
(0.49)[6.78]\end{array}$ & \\
\hline
\end{tabular}


TABLE 3: (Continued)

PANEL C: Confidence Rating Descriptive Statistics - Mean, (Standard Deviation), [Median]

\begin{tabular}{|c|c|c|c|c|}
\hline & \multicolumn{3}{|c|}{ Environmental Uncertainty } \\
\hline & & Low & High & Overall \\
\hline \multirow{3}{*}{. } & Point & $\begin{array}{c}59.67 \% \\
(12.05 \%)[60.00 \%]\end{array}$ & $\begin{array}{c}43.33 \% \\
(11.06 \%)[50.00 \%]\end{array}$ & $\begin{array}{c}51.50 \% \\
(12.91 \%)[50.00 \%]\end{array}$ \\
\hline & Range & $\begin{array}{c}62.67 \% \\
(10.16 \%)[70.00 \%]\end{array}$ & $\begin{array}{c}40.67 \% \\
(15.99 \%)[50.00 \%]\end{array}$ & $\begin{array}{c}51.67 \% \\
(15.59 \%)[55.00 \%]\end{array}$ \\
\hline & Overall & $\begin{array}{c}61.17 \% \\
(11.00 \%)[70.00 \%]\end{array}$ & $\begin{array}{c}42.00 \% \\
(13.49 \%)[50.00 \%]\end{array}$ & \\
\hline
\end{tabular}

Table 3 presents descriptive statistics - Mean (Standard Deviation), and [Median] for the difference in investors' stock price estimates: post manipulation price estimate - pre manipulation price estimate (Panel A), post manipulation stock price estimates (Panel B), and investors' confidence ratings for their post manipulation price estimates (Panel C). The shaded areas represent the two conditions where Environmental Uncertainty and Forecast Precision do not align (i.e. Low Environmental Uncertainty/Range Forecast, High Environmental Uncertainty/Point Forecast). 
given my large sample size $(n=120)$, the central limit theorem ensures that parametric tests are robust to deviation from Gaussian distributions (Scheffé 1959). Therefore, since parametric tests are more powerful than non-parametric analyses, I utilize parametric tests to analyze my data. ${ }^{16}$

When describing simple main effects, I focus on simple effects within each environmental uncertainty level rather than within each precision level. Since management has little control over the level of environmental uncertainty in which a firm operates, at least over the time horizon in which management must choose a level of forecast precision, analyzing simple effects within levels of environmental uncertainly is more informative about the potential effects of managements' alternative disclosure choices.

\section{Effects of Misalignment - Credibility}

$\mathrm{H} 1$ predicts that ratings of management credibility will be lower in cases where investors' expectations of environmental uncertainty and the precision of a management forecast do not align (i.e. High Uncertainty/Point Forecast and Low Uncertainty/Range Forecast) than when they align.

To test H1, I first assess whether responses to the Trustworthiness and Competence questions represent the same underlying credibility construct by performing a reliability analysis. The resulting Cronbach's alpha is 0.81 , well above the recommended threshold of 0.70 (Nunnally, 1978). Therefore, I combine the management trustworthiness and competence estimates into one credibility measure by averaging the two responses. ${ }^{17}$ Next, I run an ANCOVA with Credibility as the

${ }^{16}$ Performing non-parametric tests for the Credibility (H1), Growth (H2), Stock Price (H3), and Confidence (H4) hypotheses leads to similar inferences: $\mathrm{H} 1 \mathrm{p}=0.018, \mathrm{H} 2 \mathrm{p}=0.107, \mathrm{H} 3 \mathrm{p}=0.039, \mathrm{H} 4$ $\mathrm{p} \leq 0.001$.

${ }^{17}$ Results are not affected if I replace the credibility measure with either the trustworthiness or competence measures. 
dependent variable and ExperienceType as a covariate. The mean Credibility responses for each cell of the $2 \times 2$ design are provided in Panel A of Table 4. ANCOVA results in Panel $\mathrm{B}$ of Table 4 show a significant Uncertainty $\mathrm{x}$ Precision interaction $(\mathrm{p}=0.018)^{18}$, supporting $\mathrm{H} 1$.

As the focus of my analysis is on how forecast precision impacts investors' judgments given ex-ante expectations induced by environmental uncertainty, I analyze simple effects within each environmental uncertainty setting (i.e. Low Uncertainty: point vs. range; High Uncertainty: point vs. range) while maintaining ExperienceType as a covariate. Simple effects tests presented in Panel C of Table 4 show that, as predicted, credibility responses in both uncertainty scenarios are different from one another. In the Low Uncertainty setting, credibility assessments are significantly higher when a point forecast is issued than when a range forecast is issued (one-sided $\mathrm{p}=0.026$ ), while, in the High Uncertainty setting, credibility assessments are marginally significantly higher when a range forecast is issued than when a point forecast is issued (one-sided $\mathrm{p}=0.075) .^{19}$

\section{Effects of Misalignment - Growth}

H2 predicts lower future firm growth expectations in cases where investors' expectations of environmental uncertainty and the precision of management forecast do not align. To test $\mathrm{H} 2$, I run an ANCOVA with Growth as the dependent variable and ExperienceType as a covariate. The mean Growth expectations for each cell of the

\footnotetext{
${ }^{18}$ Excluding the ExperienceType covariate from the model does not affect inferences and leads to a significant Uncertainty*Precision interaction $(\mathrm{p}=0.012)$.

${ }^{19}$ Simple effects may also be analyzed within each forecast precision setting. Within the Point Forecast setting, Credibility perceptions in the Low Uncertainty treatment are significantly higher than Credibility perceptions in the High Uncertainty treatment (one-sided $\mathrm{p}<0.001$ ); within the Range Forecast setting, Credibility perceptions in the High Uncertainty treatment are not significantly higher than Credibility perceptions in the Low Uncertainty treatment (one-sided $\mathrm{p}=0.412$ ).
} 
TABLE 4: Test of H1

PANEL A: Mean Credibility Perceptions

\begin{tabular}{|c|c|c|c|c|}
\hline & \multicolumn{3}{|c|}{ Environmental Uncertainty } \\
\hline & & Low & High & Overall \\
\hline \multirow{3}{*}{ 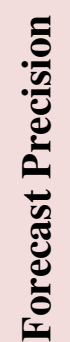 } & Point & 4.98 & 4.08 & 4.53 \\
\hline & Range & 4.43 & 4.40 & 4.42 \\
\hline & & 4.71 & 4.24 & \\
\hline
\end{tabular}

PANEL B: Analysis of Covariance for Credibility given ExperienceType

\begin{tabular}{lcrrrrr} 
Source & DF & Seq SS & Adj SS & Adj MS & F & P \\
\hline ExperienceType & 1 & 2.008 & 0.773 & 0.773 & 0.88 & 0.351 \\
Uncertainty & 1 & 5.990 & 6.120 & 6.120 & 6.93 & 0.010 \\
Precision & 1 & 0.292 & 0.317 & 0.317 & 0.36 & 0.550 \\
Uncertainty*Precision & 1 & 5.058 & 5.058 & 5.058 & 5.73 & 0.018 \\
Error & 115 & 101.577 & 101.577 & 0.883 & & \\
Total & 119 & 114.925 & & & &
\end{tabular}

\section{PANEL C: Simple Main Effects given ExperienceType}

Low Uncertainty treatments: Point $>$ Range p-value $=0.026$

High Uncertainty treatments: Range $>$ Point p-value $=0.075$

Panel A of Table 4 presents mean Credibility perceptions - Credibility is obtained by averaging participant Trustworthiness and Competence ratings. Panel B presents the results of an ANCOVA with Credibility as the dependent variable, Environmental Uncertainty, Forecast Precision, and their interaction as independent variables, and ExperienceType as a covariate (where ExperienceType = none, personal, professional, or both). Panel C presents the results of Simple Main Effects of Precision on Credibility given each Environmental Uncertainty scenario. 
TABLE 5: Test of $\mathbf{H 2}$

PANEL A: Mean Growth Expectations

\begin{tabular}{|c|c|c|c|c|}
\hline & \multicolumn{3}{|c|}{ Environmental Uncertainty } \\
\hline & & Low & High & Overall \\
\hline \multirow{3}{*}{ 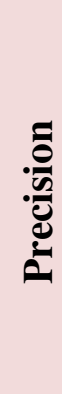 } & Point & 4.07 & 3.77 & 3.92 \\
\hline & Range & 3.70 & 4.00 & 3.85 \\
\hline & Overall & 3.88 & 3.88 & \\
\hline
\end{tabular}

PANEL B: Analysis of Covariance for Growth given ExperienceType

\begin{tabular}{lcrrrrr} 
Source & DF & Seq SS & Adj SS & Adj MS & F & P \\
\hline ExperienceType & 1 & 0.871 & 0.511 & 0.511 & 0.61 & 0.438 \\
Uncertainty & 1 & 0.006 & 0.004 & 0.004 & 0.00 & 0.948 \\
Precision & 1 & 0.083 & 0.093 & 0.093 & 0.11 & 0.741 \\
Uncertainty*Precision & 1 & 2.385 & 2.385 & 2.385 & 2.83 & 0.095 \\
Error & 115 & 97.022 & 97.022 & 0.844 & & \\
Total & 119 & 100.367 & & & &
\end{tabular}

\section{PANEL C: Simple Main Effects given ExperienceType}

Low Uncertainty treatments: Point $>$ Range p-value $=0.085$

High Uncertainty treatments: Range $>$ Point p-value $=0.172$

Panel A of Table 5 presents mean Growth expectations. Panel B presents the results of an ANCOVA with Growth as the dependent variable, Environmental Uncertainty, Forecast Precision, and their interaction as independent variables, and ExperienceType as a covariate (where ExperienceType = none, personal, professional, or both). Panel C presents the results of Simple Main Effects of Precision on Growth given each Environmental Uncertainty scenario. 
$2 \times 2$ design are provided in Panel A of Table 5. ANCOVA results in Panel B of Table 5 show a marginally significant Uncertainty $x$ Precision interaction $(p=0.095)$, supporting $\mathrm{H} 2 .^{20}$

I again focus on simple main effects for precision within each environmental uncertainty setting while maintaining ExperienceType as a covariate. Simple effects tests in Panel $\mathrm{C}$ of Table 5 show that growth expectations are marginally significantly higher when a point forecast is issued than when a range forecast is issued (one-sided $\mathrm{p}=0.085$ ) in the Low Uncertainty setting, but do not significantly differ between point and range scenarios in the High Uncertainty setting (one-sided $\mathrm{p}=0.172$ ). ${ }^{21}$

\section{Effects of Misalignment - Stock Price Estimates}

H3 predicts that investors' stock price estimates will be lower in the misalignment scenarios than in the alignment scenarios. To test H3, I first determine the difference in stock price estimates for each participant by subtracting the premanipulation stock price estimates from the post-manipulation stock price estimates. Next, I run an ANCOVA with PriceDifference as the dependent variable and ExperienceType as a covariate. The mean PriceDifference estimates for each cell of the $2 \times 2$ design are provided in Panel A of Table 6. ANCOVA results in Panel B of Table 6 show a significant Uncertainty x Precision interaction $(\mathrm{p}=0.039)$, supporting H3. ${ }^{22,23}$

\footnotetext{
${ }^{20}$ Excluding the ExperienceType covariate from the model does not affect inferences and leads to a marginally significant Uncertainty*Precision interaction ( $\mathrm{p}=0.076$ ).

${ }^{21}$ Simple effects may also be analyzed within each forecast precision setting. Within the Point Forecast setting, Growth expectations in the Low Uncertainty treatment are marginally significantly higher than Growth expectations in the High Uncertainty treatment (one-sided p-value $=0.08$ ); within the Range Forecast setting, Growth expectations in the High Uncertainty treatment are not significantly greater than Growth expectations in the Low Uncertainty treatment (one-sided p-value $=0.112$ ).

${ }^{22}$ Excluding the ExperienceType covariate from the model does not affect inferences and leads to a marginally significant Uncertainty*Precision interaction ( $\mathrm{p}=0.079)$.

${ }^{23}$ Performing the same ANCOVA analysis with PostTreatmentPrice instead of PriceDifference as the dependent variable leads to similar results $(\mathrm{p}=0.053)$.
} 
TABLE 6: Test of $\mathrm{H3}$

PANEL A: Mean PriceDifference Estimates

\begin{tabular}{|c|c|c|c|c|}
\hline & \multicolumn{3}{|c|}{ Environmental Uncertainty } \\
\hline & & Low & High & Overall \\
\hline \multirow{3}{*}{ 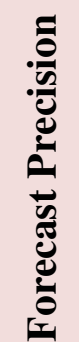 } & Point & 0.93 & 0.58 & 0.76 \\
\hline & Range & 0.72 & 0.69 & 0.71 \\
\hline & Overall & 0.83 & 0.64 & \\
\hline
\end{tabular}

PANEL B: Analysis of Covariance for PriceDifference given ExperienceType

\begin{tabular}{lcrrrrr} 
Source & DF & Seq SS & Adj SS & Adj MS & F & P \\
\hline ExperienceType & 1 & 0.820 & 1.282 & 1.282 & 5.74 & 0.018 \\
Uncertainty & 1 & 1.280 & 1.307 & 1.307 & 5.86 & 0.017 \\
Precision & 1 & 0.110 & 0.116 & 0.116 & 0.52 & 0.472 \\
Uncertainty*Precision & 1 & 0.973 & 0.973 & 0.973 & 4.36 & 0.039 \\
Error & 115 & 25.665 & 25.665 & 0.223 & & \\
Total & 119 & 28.847 & & & &
\end{tabular}

\section{PANEL C: Simple Main Effects given ExperienceType}

Low Uncertainty treatments: Point $>$ Range p-value $=0.043$

High Uncertainty treatments: Range $>$ Point p-value $=0.140$

Panel A of Table 6 presents mean Price Difference estimates (where Price Difference $=$ Post Manipulation Price Estimate - Pre Manipulation Price Estimate). Panel B presents the results of an ANCOVA with PriceDifference as the dependent variable, Environmental Uncertainty, Forecast Precision, and their interaction as independent variables, and ExperienceType as a covariate (where ExperienceType = none, personal, professional, or both). Panel C presents the results of Simple Main Effects of Precision on PriceDifference given each Environmental Uncertainty scenario. 
I again focus on simple main effects for precision within each environmental uncertainty setting, while maintaining ExperienceType as a covariate. As shown in Panel C of Table 6, regressing PriceDifference on Precision and ExperienceType in the Low Uncertainty treatments indicates that issuing a point forecast leads to significantly greater price estimates than issuing a range forecast (one-sided $p=0.043$ ) when uncertainty is low. However, following the same procedure in the High Uncertainty treatments suggests that issuing a range forecast does not lead to significantly different price estimates than does issuing a point forecast (one-sided $\mathrm{p}=0.140)$ when uncertainty is high. ${ }^{24}$

\section{Effects of Misalignment - Mediation Analyses}

I also make predictions about several mediation paths between the independent variables and dependent variables. Specifically, as depicted in Figure 1, I predict that 1) participants' perceptions of management credibility will mediate the relationship between the independent variables (of environmental uncertainty and forecast precision) and growth expectations. Next, because growth expectations factor into stock price estimates, I also expect that 2) growth expectations will act as a mediator between the independent variables and stock price estimates. Further, given the overall path suggested by the above two mediations (i.e. independent variables $\rightarrow$ credibility perceptions $\rightarrow$ growth expectations $\rightarrow$ stock price estimates), I predict that: 3) credibility should also mediate the relationship between the independent variables and stock price estimates and that 4) growth expectations should mediate the relationship between credibility perceptions and stock price estimates. Figure 3

\footnotetext{
${ }^{24}$ Simple effects may also be analyzed within each forecast precision setting. Within the Point Forecast setting, PriceDifference estimates in the Low Uncertainty treatment are significantly higher than PriceDifference estimates in the High Uncertainty treatment (one-sided p-value $=0.002$ ); PriceDifference estimates in the Range Forecast setting are not significantly different across the two uncertainty levels (one-sided p-value $=0.425$ ).
} 


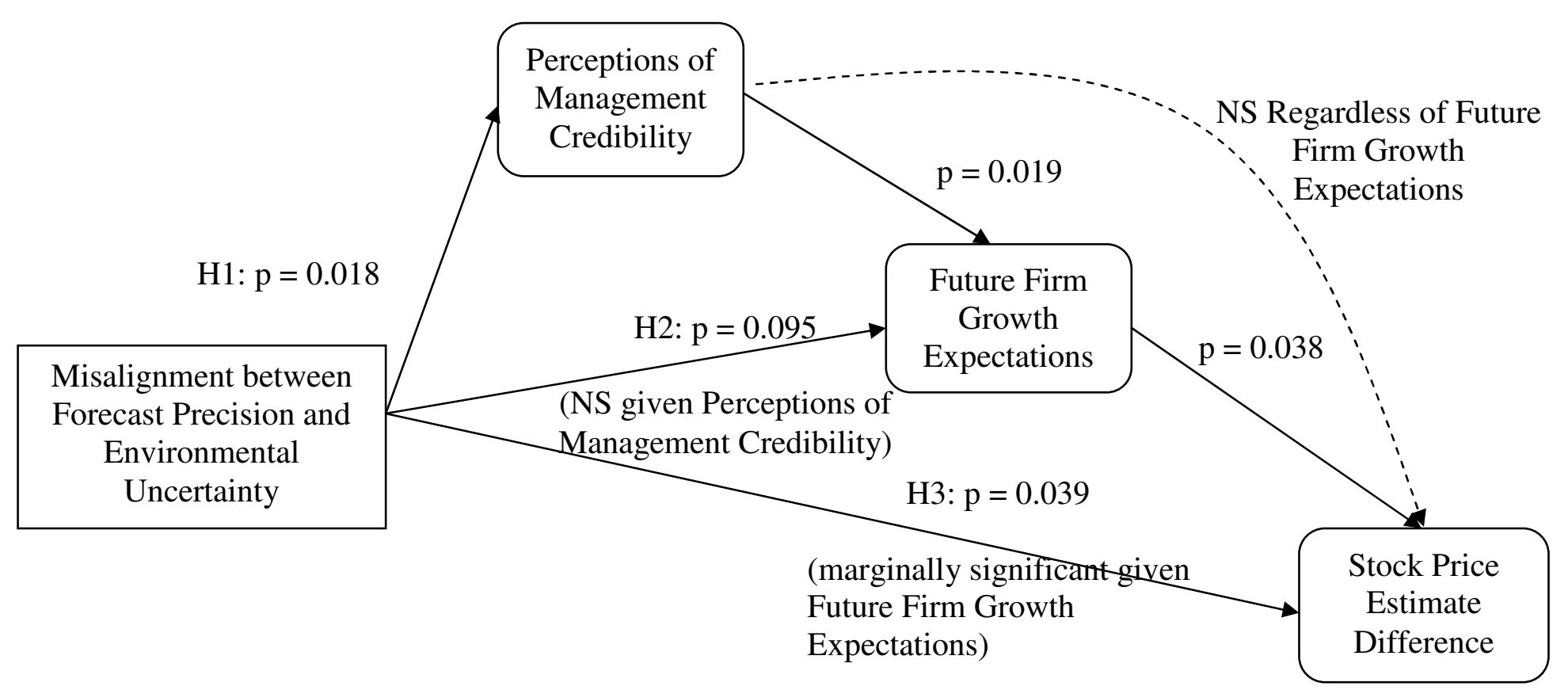

\section{FIGURE 3: Overall Results}

Figure 3 provides a graphical representation of the results for and links between H1 through H3. Solid lines represent significant relationships between model components, while a dotted line represents the lack of a significant relationship between two components; NS = Not significant. 
summarizes the mediation analyses results described below.

According to Baron and Kenny (1986) and Kenny, Kashy and Bolger (1998), four steps must be carried out to confirm mediation: 1) show that the independent variable is correlated with the dependent variable, 2) show that the independent variable is correlated with the mediator, 3) show that the mediator is correlated with the dependent variables, and 4) show that the relationship between the independent variables and the dependent variables becomes less significant when the mediator is included in the model. When applying these steps to the analysis of credibility as a mediator between misalignment and growth expectations, results of $\mathrm{H} 2$ satisfy the first step of the Baron and Kenny (1986) analysis, and results of H1 satisfy step 2. Table 7 reports results of steps 3 and 4. Credibility perceptions and Growth expectations are significantly positively correlated $(\mathrm{p}=0.019)$ satisfying step 3 . Once Credibility is added as a covariate in the model testing $\mathrm{H} 2$, the Uncertainty $\mathrm{x}$ Precision interaction loses significance (p-value decreases from 0.095 to 0.232 ), satisfying step 4 . Performing the Sobel test further confirms that perceptions of management credibility mediate the relationship between misalignment and investors' perceptions of future firm growth (one-sided $\mathrm{p}=0.04){ }^{25}$

Since future firm growth expectations factor into investors' stock price estimates, I expect that these two dependent variables are significantly correlated, and more so, that growth expectations mediate the relationship between misalignment and stock price estimates. Step 3 of Table 8 shows that Growth and PriceDifference are significantly positively correlated $(\mathrm{p}=0.038)$. Further, remaining results presented in Table 8 support the prediction that growth expectations mediate the relationship

\footnotetext{
${ }^{25}$ The Sobel test is a one step test of whether a mediator carries the influence of an independent variable to a dependent variable with the advantage of displaying a significance level for the mediation of interest. Using Monte Carlo simulation MacKinnon, Warsi, and Dwyer (1995) show that the Sobel test and the Baron and Kenny (1986) analysis performed equally well in sample sizes of above 50.
} 


\section{TABLE 7: Test of Mediation for Credibility Perceptions}

\section{Baron and Kenny (1986) steps with Growth as dependent variable:}

Step 1: satisfied via significance of $\mathrm{H} 2$

Step 2: satisfied via significance of $H 1$

Step 3: Credibility and Growth perceptions significantly positively correlated

Correlation coefficient $=0.225$

P-Value $=0.019$

Step 4: Effect of Misalignment on Growth becomes insignificant once include Credibility in the model

\begin{tabular}{|c|c|c|c|c|c|c|}
\hline Source & DF & Seq SS & Adj SS & Adj MS & $\mathbf{F}$ & $\mathbf{P}$ \\
\hline ExperienceType & 1 & 0.871 & 0.297 & 0.297 & 0.36 & 0.548 \\
\hline Credibility & 1 & 4.615 & 3.701 & 3.701 & 4.52 & 0.036 \\
\hline Uncertainty & 1 & 0.346 & 0.267 & 0.267 & 0.33 & 0.569 \\
\hline Precision & 1 & 0.030 & 0.039 & 0.039 & 0.05 & 0.829 \\
\hline Uncertainty*Precision & 1 & 1.184 & 1.184 & 1.184 & 1.45 & 0.232 \\
\hline Error & 114 & 93.322 & 93.322 & 0.819 & & \\
\hline Total & 119 & 100.367 & & & & \\
\hline
\end{tabular}

Table 7 presents results of the Baron and Kenny (1986) steps for mediation, testing whether Credibility mediates the relationship between Misalignment and Growth expectations. 


\section{TABLE 8: Test of Mediation for Growth Expectations}

Baron and Kenny (1986) steps with PriceDifference as dependent variable:

Step 1: satisfied via significance of $\mathrm{H3}$

Step 2: satisfied via significance of $\mathrm{H} 2$

Step 3: Growth and PriceDifference perceptions significantly positively correlated Correlation Coefficient $=0.101$

P-value $=0.038$

Step 4: Effect of Misalignment on PriceDifference reduces from significant to marginally significant once include Growth in the model

Analysis of Covariance for PriceDifference given ExperienceType and Growth

\begin{tabular}{lcrrrrr} 
Source & DF & Seq SS & Adj SS & Adj MS & F & P \\
\hline ExperienceType & 1 & 0.820 & 1.420 & 1.420 & 6.50 & 0.012 \\
Growth & 1 & 1.014 & 0.747 & 0.747 & 3.42 & 0.067 \\
Uncertainty & 1 & 1.297 & 1.319 & 1.319 & 6.04 & 0.016 \\
Precision & 1 & 0.091 & 0.099 & 0.099 & 0.45 & 0.503 \\
Uncertainty*Precision & 1 & 0.707 & 0.707 & 0.707 & 3.23 & 0.075 \\
Error & 114 & 24.918 & 24.918 & 0.219 & & \\
Total & 119 & 28.847 & & & &
\end{tabular}

Panel A of Table 8 presents the results of the strength of a relationship between Growth expectations and PriceDifference (where Price Difference $=$ Post Treatment Price Estimate - Pre Treatment Price Estimate). Panel B presents results of the Baron and Kenny (1986) steps for mediation, testing whether Growth mediates the relationship between Misalignment and PriceDifference Estimates. 
between misalignment and PriceDifference estimates (as adding Growth into the model testing H3 - with PriceDifference as the dependent variable - decreases the interaction $\mathrm{p}$-value from 0.039 to 0.075 ; Sobel test one-sided $\mathrm{p}=0.07$ ).

When applying the above steps to the analysis of credibility as a mediator between misalignment and stock price estimates, results of $\mathrm{H} 3$ satisfy the first step of the Baron and Kenny (1986) analysis, while results of H1 satisfy step 2. However, performing step 3 results in a non-significant correlation coefficient of 0.003 $(p=0.956)$ suggesting that perceptions of management credibility cannot be a mediator for the relationship between misalignment and investors' stock price estimates.

Finding that perceptions of credibility mediate the relationship between misalignment and growth expectations (i.e. Table 7), and that growth expectations mediate the relationship between misalignment and stock price estimates, suggests an indirect relationship between management credibility and stock price estimates. That is, perceptions of management credibility affect growth expectations which in turn affect stock price estimates. Note however, that it is not possible for growth expectations to serve as a mediator between perceptions of credibility and price difference estimates, since the latter two judgments are not significantly correlated $(\mathrm{p}=0.956)$.

\section{Effects of Misalignment - Signaling Hypothesis}

Signaling theory suggests the possibility that investors will consider a point forecast issued in a highly uncertain environment as a signal of positive private information and thus increase their ratings of management credibility. Given support for H1, investors' stock price estimates follow the pattern predicted by attribution theory rather than the predictions of signaling theory. Therefore, considerations of management possessing positive private information cannot serve as a mediator 
between misalignment and stock price estimates. An insignificant association between PrivateInformation and PriceDifference (untabulated) supports the lack of mediation $(\mathrm{p}=0.163)$. PrivateInformation also does not serve as a mediator between misalignment and growth expectations, since PrivateInformation and Growth are not significantly correlated $(\mathrm{p}=0.303)$. Thus, although some portion of participants considered signaling by management, signaling considerations do not play a significant role in the model presented in Figure 1.

Since it appears that some participants considered signaling effects while others responded to misalignment by adjusting their credibility perceptions and growth expectations, I rerun all of the above analyses while controlling for how strongly participant considerations of signaling affected their stock price estimates (i.e. including a self-report measure of Private Information Importance $=$ Not at all Important in Estimating Price, Not Very Important in Estimating Price, Somewhat Important in Estimating Price, Very Important in Estimating Price). Untabulated results suggest that the significance of $\mathrm{H} 1, \mathrm{H} 3$, and the credibility mediation analyses is not affected, but that the significance of $\mathrm{H} 2$ improves from $\mathrm{p}=0.095$ to $\mathrm{p}=0.052$, and that the significance of growth as a mediator between misalignment and stock price estimates improves from Sobel one-sided $\mathrm{p}=0.07$ to $\mathrm{p}=0.050$.

\section{Confidence in EPS Estimates}

H4 predicts that confidence in participants' stock price estimates will be highest when environmental uncertainty is low and management discloses a point forecast, and lowest when environmental uncertainty is high and management discloses a range forecast. This hypothesis is equivalent to two main effects of precision and uncertainty.

The mean Confidence responses for each cell of the $2 \times 2$ design are provided in 
TABLE 9: Test of $\mathrm{H4}$

PANEL A: Mean Confidence in Price Estimate

\begin{tabular}{|c|c|c|c|c|}
\hline & & \multicolumn{3}{|c|}{ Environmental Uncertainty } \\
\hline & & Low & High & Overall \\
\hline \multirow{3}{*}{ 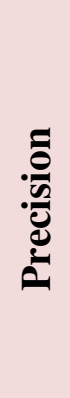 } & Point & $59.67 \%$ & $43.33 \%$ & $\mathbf{5 1 . 5 0 \%}$ \\
\hline & Range & $62.67 \%$ & $40.67 \%$ & $51.67 \%$ \\
\hline & Overall & $61.17 \%$ & $42.00 \%$ & \\
\hline
\end{tabular}

PANEL B: Analysis of Covariance for Confidence Estimates given

Experience Type

\begin{tabular}{lcrrrrr} 
Source & DF & Seq SS & Adj SS & Adj MS & F & P \\
\hline ExperienceType & 1 & 0.223 & 0.041 & 0.041 & 0.01 & 0.929 \\
Uncertainty & 1 & 110.142 & 109.795 & 109.795 & 21.65 & $<0.001$ \\
Precision & 1 & 0.003 & 0.005 & 0.005 & 0.00 & 0.974 \\
Uncertainty*Precision & 1 & 2.298 & 2.298 & 2.298 & 0.45 & 0.502 \\
Error & 115 & 583.326 & 583.326 & 5.072 & & \\
Total & 119 & 695.992 & & & &
\end{tabular}

Panel A of Table 9 presents mean Confidence estimates. Panel B presents the results of an ANCOVA with Confidence as the dependent variable, Environmental Uncertainty, Forecast Precision, and their interaction as the independent variables, and ExperienceType as a covariate.

Panel A of Table 9 and suggest that Confidence ratings are high (low) when issuing a forecast in a low (high) uncertainty setting but do not differ across precision levels. ANCOVA results in Panel B of Table 9 confirm a significant main effect for uncertainty $(\mathrm{p}<0.001)$ but, contrary to prior forecast precision studies, no effect for precision ( $\mathrm{p}=0.974)$. H3 is only partially supported. 


\section{CHAPTER 5}

\section{CONCLUSION}

Over the past two decades, earnings forecasts have become a major component of firms' voluntary disclosures (Cotter et al. 2006). Management uses earnings forecasts either to adjust market expectations regarding future firm performance (Ajinkya and Gift 1984) or simply to confirm that current expectations are accurate (Clement, Frankel, and Miller 2003). While it is well-documented that the actual earnings prediction is value-relevant, little evidence exists to suggest that the precision of this prediction is also important. My study contributes to the earnings forecast literature by 1) showing that forecast precision matters prior to earnings announcements, 2) identifying investors' expectations as a reason why forecast precision matters, and 3) beginning to explain the process behind how forecast precision affects investors' stock price estimates and perceptions of firm growth.

Results indicate that the precision of management earnings forecasts and environmental uncertainty interact to affect investors' assessments of management credibility, earnings growth, and stock price, with all of those assessments being lower when precision and uncertainty are misaligned. Specifically, given low (high) environmental uncertainty, stock price estimates are lower when management issues a misaligned range (point) earnings forecast than when management issues an aligned point (range) earnings forecast. This result is in contrast to prior behavioral research, which does not find any effect for the precision of management forecasts on firm valuation estimates immediately following forecast issuance. As a practical matter, this result suggests that a manager who wants to communicate good news and who desires that investors 1) view the manager as credible, 2) predict higher earnings 
growth, and 3) estimate a higher stock price, should issue range forecasts when in a high uncertainty environment and point forecasts when in a low uncertainty environment.

Examining the simple effects in a different direction, my results indicate a strong effect of environmental uncertainty on investors' judgments when investors are provided a point forecast, but virtually no effect on any of investors' judgments when they are provided a range forecast. Thus environmental uncertainty is more damaging to investors' judgments given more precise forecast information, with investors rewarding a precise forecast under low uncertainty but penalizing a precise forecast under high uncertainty, relative to what investors would do when provided a range forecast. This finding is consistent with post-earnings-announcement results in LTH where investor responses to guidance error following point forecasts were significantly more extreme than investor responses following wide range forecasts. Combining the results of both studies suggests that the market significantly rewards, but also significantly punishes firms issuing point forecasts rather than wide range forecasts. Given the potential for such negative market reaction immediately after forecast issuance and following subsequent earnings announcement may explain the less prominent occurrence of point forecasts, rather than range forecasts, in firm earnings disclosures (e.g. see Baginski et al. 2007).

I expected that perceptions of management credibility would mediate the effect of misalignment on growth expectations and stock price. However, perceptions of management credibility only mediate the relationship between misalignment and growth expectations, and not the relationship between misalignment and stock price estimates. A potential explanation for this unexpected result lies in the components of stock price estimates. That is, stock price estimates can be viewed as a product of EPS and P/E multiple expectations. Prior credibility research has only found a link 
between perceptions of credibility and P/E multiple estimates (also supported by the current study if we assume that perceptions of growth proxy for $\mathrm{P} / \mathrm{E}$ multiple estimates), but no relationship between credibility and EPS estimates (Barton and Mercer 2005; Hirst, Koonce, Venkatarman 2007). Combining both EPS and P/E multiple expectations into one stock price estimate may therefore lessen the strength with which management credibility mediates misalignment and stock price estimates. $^{26}$ Further, there may not be enough variation in credibility perceptions to drive investor stock price estimates. However, together with a significant effect of misalignment on perceptions of credibility (i.e. results for $\mathrm{H} 1$ ), the lack of a relationship between credibility and stock price estimates suggests that misalignment between environmental uncertainty and forecast precision should be of considerable concern to management. That is, misalignment lowers investors' perceptions of management credibility as well as, and apart from, investors' valuation of the firm's stock price.

My results also suggest that expectation about environmental uncertainty significantly affect investors' confidence in their stock price estimates, but results do not confirm prior findings of the effect of forecast precision on investors' confidence in their estimates. A potential explanation for the lack of a main effect for earnings forecast precision is the difference in dependent variables between my study and prior studies. Hirst et al. (1999) and LTH each elicit EPS estimates - the same types of estimates provided by management in an earnings forecast. It is then reasonable for an investor making an EPS estimate to find the precision level of the same EPS estimate provided by management to be very informative. My study elicits stock price estimates which, while informed by firm EPS forecasts, also encompass other and

\footnotetext{
${ }^{26}$ Pilot testing of the current study suggests that when EPS estimates are elicited instead of stock price estimates, perceptions of management credibility do not mediate the relationship between misalignment and EPS estimates.
} 
more forward looking performance indicators. It is therefore understandable that the precision of one indicator carries less weight in determining confidence in the overall stock price estimate. $^{27}$

My results are subject to several limitations. First, due to time constraints, participants' task is a simplification of the financial statement analysis task that would be required to provide firm stock price estimates. Participants are asked to assume that they have already completed a majority of their analysis prior to encountering the earnings forecast that is the focus of my experiment. Although this assumption affects the realism of my design, it should not impact the direction of participant responses. Second, the study was administered online rather than in person. Although allowing participants to access the study independently at any point during a pre-specified period of time inherently surrenders some experimental control in administering the study, the potential increased variability in responses should work against obtaining predicted results. Further, prior convergent validity research in accounting has shown no significant differences in the results of in-lab and out-of-lab experiments (Alexander, Blay, and Hurtt 2006).

\footnotetext{
${ }^{27}$ Pilot testing of the current study suggests that when EPS estimates are elicited instead of stock price estimates, both a main effect for uncertainty and a main effect for precision are significant $(\mathrm{p}<0.001$ for each).
} 


\section{APPENDIX \\ PILOT EXPERIMENT}

\section{Hypotheses}

Pilot Experiment hypotheses were similar to the hypotheses described in Chapter 2 with two main exceptions. First, in contrast to the dependent variables that are the focus of $\mathrm{H} 2$ and $\mathrm{H} 3$, in the pilot study I elicit forecasts of Earnings per Share (EPS). Therefore, I also elicit participant assessments of confidence in their EPS forecasts as opposed to their stock price estimates. Second, I focus on the components of management credibility (i.e. competence and trustworthiness) and predict that the relative impact of each component will be different depending on the experimental treatment. Below I explain these two exceptions in more detail.

Hypothesis 1 does not vary across the pilot and primary experiments.

Pilot H1: Perceptions of management credibility are lower when expectations about environmental uncertainty and precision of positive news forecasts do not align than when they align.

However, the main measure of investor and analyst behavior in forecast precision studies has been an EPS forecast. Extending those studies, I predict that EPS forecasts will follow the same pattern as do perceptions of management credibility, being less favorable when environmental uncertainty and forecast precision do not align than when they align.

Pilot H2: EPS forecasts are lower when expectations about environmental uncertainty and precision of positive news forecasts do not align than when they align. 
Eliciting EPS forecasts also slightly alters the focus of my confidence-inestimates hypothesis, as I ask participants to assess the confidence in their EPS forecasts.

Pilot H3: Investors' confidence in their EPS forecasts is highest (lowest) in response to point (range) earnings forecasts evaluated with an expectation of low (high) environmental uncertainty.

I also rely on prior literature to make predictions regarding specific investor perceptions of management competence and trustworthiness. Specifically, the negative inferences that investors make about management credibility may depend on the particular misalignment between expected and actual forecast precision. Prior psychology research has established that two main components of source credibility are competence and trustworthiness (Hovland, Janis, and Kelley 1953, Griffin 1967).

Consider the misalignment scenario in which management discloses a positive earnings forecast that is precise but investors perceive high uncertainty in the firm's environment. This misalignment is likely to lead investors to question why the forecast is so precise. Attribution theory predicts that investors will answer this question with attributions to management character. Yet it seems less likely that investors will view management as untrustworthy, since the accuracy of a precise forecast can be clearly verified once management makes the actual earnings announcement several weeks later. If management did issue a dishonest forecast, the effect of the forecast would only be temporary and management would be severely punished once the forecast was revealed as inaccurate. Therefore, in this setting it is more probable that investors will perceive the manager as less competent and overzealous in the precision of his estimates. ${ }^{28}$

\footnotetext{
${ }^{28}$ Another possibility when managers make overly precise forecasts in an uncertain environment is that they are capable of managing their earnings to achieve the precise forecast (see, e.g., Nelson, Elliott, and Tarpley 2002). In the pilot experiment I limit this possible inference by informing participants that
} 
Pilot H4: When investors perceive high environmental uncertainty but management discloses a precise forecast, lower perceptions of management credibility occur mainly through investor perceptions of management competence.

Now consider the second misalignment scenario in which management discloses a positive earnings forecast that is imprecise but investors perceive low uncertainty in the firm's environment. This misalignment is likely to lead investors to question why the forecast is not more precise. The low level of uncertainty in the environment dictates that a precise forecast should not be difficult to estimate. Since investors perceive relative ease in generating an earnings estimate, inability to provide a precise forecast due to lack of management competence is unlikely to be their main inference. Instead, managers appear evasive. Because an imprecise forecast allows management to disguise a not so positive prediction among a range of higher potential estimates and because management has a very strong incentive to suggest that the firm will perform better in the future, investors are more likely to infer that the cause of misalignment between their expectations and actual forecast precision is a shortcoming in management trustworthiness.

Pilot H5: When investors perceive low environmental uncertainty but management discloses an imprecise forecast, lower perceptions of management credibility occur mainly through investor perceptions of management trustworthiness.

Psychology research suggests an asymmetry in the extent to which negative attributions to competence and negative attributions to trustworthiness lead to lower perceptions of management credibility. Reeder and Brewer (1979) lay out a model circumstances to suggest an intention to manage earnings. 
which predicts that displays of low integrity (i.e., trustworthiness) are more informative than displays of low competence, because while highly competent individuals do sometimes make mistakes, highly trustworthy persons never perform acts of low integrity. As a result, attributing a misalignment to low management trustworthiness may have more negative consequences than attributing the misalignment to low management competence:

Pilot H6: Investors' perceptions of management credibility are lower when investors perceive low environmental uncertainty but management discloses an imprecise forecast than when investors perceive high environmental uncertainty but management discloses a precise forecast.

\section{Design}

I use a $2 \times 2$ between subjects design where I manipulate forecast precision (point vs. range) and the level of uncertainty in the environment (low vs. high). After viewing firm background information and experimental manipulations all participants assess management competence and trustworthiness, provide their EPS estimates, and rate their confidence in those EPS estimates.

\section{Results}

I find partial support for Pilot $\mathrm{H} 1$, such that, within a low environmental uncertainty setting, perceptions of management credibility are lower given misalignment (i.e. management issues a range forecast) than given alignment (i.e. management issues a point forecasts) between forecast precision and environmental uncertainty. However, I do not find significant differences between the point and range scenarios given high environmental uncertainty. 
In line with predictions in Pilot $\mathrm{H} 2$, within each environmental uncertainty setting EPS estimates are lower given misalignment between forecast precision and environmental uncertainty than given alignment. Findings do not, however, confirm that perceptions of management credibility mediate the relationship between misalignment and EPS estimates.

Results support the predictions in Pilot H3, such that, investors' EPS forecast confidence ratings are highest (lowest) in response to point (range) earnings forecasts evaluated with an expectation of low (high) environmental uncertainty. Results do not support the predictions in Pilot H4-H6.

\section{Adjustments Made Prior to Primary Experiment}

Given findings from the pilot experiment, I make two main adjustments to the primary experiment: 1) I fine tune my measure of management credibility, and do not attempt to test differential importance of various aspects of management credibility, and 2) I replace EPS forecasts with growth expectations and stock price estimates as the main dependent variables of interest.

I attribute the lack of an effect of misalignment on perceptions of management credibility in the high environmental uncertainty setting to a measurement problem. As a result, in the primary experiment I fine tune the credibility measure to more clearly focus on internal attributions about management credibility as opposed to management and disclosure credibility. First, I remove reference to 'financial disclosures' from both the competence and trustworthiness questions. Second, I remind participants to answer these questions keeping in mind their specific forecast precision and environmental uncertainty scenario as follows: 
Trustworthiness measure: “Given Zetha's highly certain [uncertain] operating environment and management's point [range] earnings forecast, I trust Zetha's management."

Competence measure: “Given Zetha's highly certain [uncertain] operating environment and management's point [range] earnings forecast, Zetha's management is competent."

I do not attempt to test pilot H4-H6, as I do not believe my credibility measure is powerful enough to identify the subtle effects indicated in those hypotheses.

Management credibility research focuses on the price to earnings (P/E) multiple as the main dependent variable affected by perceptions of management credibility. Further, some research argues that management credibility is conceptually more tightly linked to P/E multiples than EPS estimates (e.g. Barton and Mercer 2005). Therefore, in the primary experiment, I rely on this literature when eliciting participant future growth expectations (where growth is a major component of a $\mathrm{P} / \mathrm{E}$ multiple). Additionally, I combine the main dependent variable used in precision research (i.e. EPS forecasts) with the main dependent variable used in credibility research (i.e. P/E multiples) by asking participants to estimate the firm's price per share $($ where price per share $=\mathrm{EPS} * \mathrm{P} / \mathrm{E}$ multiple $) . \quad$ The price per share estimate also allows me to more directly test for an economic impact of precision and uncertainty. 


\section{BIBLIOGRAPHY}

Ajinkya, B. B., and Gift, M.J. (1984). Corporate managers' earnings forecasts and symmetrical adjustments of market expectations. Journal of Accounting Research, 22: 425-444.

Alexander, R.M., Blay, A., and Hurtt, R.K. (2006). An Examination of convergent validity between in-lab and out-of-lab internet-based experimental accounting research. Behavioral Research in Accounting, Vol. 18: 207-217.

Atiase, R., Li, H., Supattarakul, S., and Tse, T. (2005). Market reaction to multiple contemporaneous earnings signals: Earnings announcements and future precision on equity pricing and on the assessment of earnings uncertainty. The Accounting Review, 68: 913-927.

Baginski, S. P., and Hassell, J. M. (1990). The market interpretation of management earnings forecasts as a predictor of subsequent financial analyst forecast revision. The Accounting Review, Vol. 6 (1): 175-190.

Baginski, S.P., Conrad, E.J., and Hassell, J.M. (1993). The effects of management forecast

Baginski, S.P., Hassell, J.M., and Weiland, M.M. (2007). Does management earnings forecast form matter? Working Paper: University of Georgia.

Bamber, L.S. and Cheon, Y.S. (1998). Discretionary management earnings forecast disclosures: antecedents and outcomes associated with forecast venue and forecast specificity choices. Journal of Accounting Research, Vol. 36 (2): 167190.

Baron, R.M. and D.A. Kenny. 1986. The moderator-mediator variable distinction in social psychological research: Conceptual, strategic, and statistical considerations. Journal of Personality and Social Psychology. 51(6): 1173 1182.

Barton, J., and Mercer, M. (2005). To blame or not to blame: analysts' reactions to external explanations for poor financial performance. Journal of Accounting and Economics, 39: 509-533.

Clement, M., Frankel, R., and Miller, J. (2003). Confirming management earnings forecasts, earnings uncertainty, and stock returns. Journal of Accounting Research, 41 (4): 653-679.

Clor-Proell, S.M. (2009). The effects of expected and actual accounting choices on 
judgments and decisions. The Accounting Review, Vol. 84 (5): 1465-1493.

Clor-Proell, S., and Maines, L. (2009). Reliability of Recognized versus Disclosed Information in Financial Statements: A Preparer's Perspective. Working Paper: San Diego State University.

Cotter, J., Tuna, I., and Wysocki, P.D. (2006). Expectations management and beatable targets: how do analysts react to explicit earnings guidance? Contemporary Accounting Research, 23: 593-624.

Fiske, S. T. and Taylor, S.E. (1991). Social cognition ( $2^{\text {nd }}$ ed.). New York: McGraw Hill.

Gilbert, D.T. and Malone, P.S. (1995). The correspondence bias. Psychological Bulletin, Vol. 117 (1): 21-38.

Graham, J.R., Harvey, C.R., and Rajgopal, S. (2005). The economic implications of corporate financial reporting. Journal of Accounting and Economics, Vol. 40 (1-3):3-73.

Griffin, K. (1967). The contribution of studies of source credibility to a theory of interpersonal trust in the communication process. Psychological Bulletin, Vol. 68 (2): 104-120.

Han, J., and Tan, H.T. (2010). Investors' reactions to management earnings guidance: the joint effect of investment position, news valence, and guidance form. Journal of Accounting Research, Vol. 48 (1): 81-104.

Hirst, D.E., Koonce, L., and Miller, J. (1999). The joint effect of management's prior forecast accuracy and the form of its financial forecasts on investor judgments. Journal of Accounting Research, 37 (Sept.): 101-124.

Hirst, D.E., Koonce, L., and Venkataraman, S. (2007): How disaggregation enhances the credibility of management earnings forecasts. Journal of Accounting Research, 45 (4).

Hovland, C.I., Janis, I.L., and Kelley, H.H. (1953). Communication and persuasion. New Haven: Yale University Press.

Hrebiniak, L.G., and Snow, C.C. (1980). Research notes: Industry differences in environmental uncertainty and organizational characteristics related to uncertainty. Academy of Management Journal, Vol. 23 (4): 750-759. 
Hutton, A.P., Miller, G.S., and Skinner, D.J. (2003). The role of supplementary statements with management earnings forecasts. Journal of Accounting Research, 41: 867-890.

Jiang, G.H., Lee, C.M.C., and Zhang, Y. (2005). Information uncertainty and expected returns. Review of Accounting Studies, Vol. 10 (2-3): 185-221.

Kenny, D. A., D.A. Kashy, and N. Bolger. (1998). Data analysis in social psychology. In D. T. Gilbert \& S. T. Fiske (Eds.), The Handbook of Social Psychology (4th ed., Vol. 1, pp. 233-265). New York, NY: McGraw-Hill.

King, R., Pownall, G., and Waymire, G. (1990). Expectations adjustments via timely management forecasts: review, synthesis, and suggestions for future research. Journal of Accounting Literature, 9: 113-144.

Kuhn, K.M. and Budescu, D.V. (1996). The relative importance of probabilities, outcomes, and vagueness in hazard risk decisions. Organizational Behavior and Human Decision Processes, Vol. 68 (3): 301-317.

Kuhn, K.M., Budescu, D.V., Hershey, J., Kramer, K., and Rantilla, A. (1999). Tradeoffs in risk attributes: The joint effects of dimension preference and vagueness. Risk, Decision and Policy, 4:1-16.

Leathers, D. (1992). Successful Nonverbal Communications: Principles and Applications. New York, NY: MacMillan.

Libby, R., Tan, H.T., and Hunton, J.E. (2006). Does the form of managements' earnings guidance affect earnings forecasts? The Accounting Review, 81: 251270.

MacKinnon, D.P., Warsi, G., and Dwyer, J.H. (1995). A simulation study of mediated effect measures. Multivariate Behavioral Research, Vol. 30 (1): 41-62.

McCroskey, J. (1966). Scales for the measurement of ethos. Speech Monographs, 33: 65-72.

Mercer, M. (2005). The fleeting effects of disclosure forthcomingness on management's reporting credibility. The Accounting Review, Vol. 80 (2): 723744.

Mueller, D. C. (1972). A life cycle theory of the firm, Journal of Industrial Economics, 20 (3): 199-219. 
Nelson, M.W., Elliott, J.A., and Tarpley, R.L. (2002). Evidence from auditors about managers' and auditors' earnings management decisions. The Accounting Review, Vol. 77 (Suppl. S): 175-202.

Newell, S.J. and Goldsmith, R.E. (2001). The development of a scale to measure perceived corporate credibility. Journal of Business Research, 52: 235-247.

Nunnally, J. (1978). Psychometric Theory. $2^{\text {nd }}$ edition. New York, NY: McGraw-Hill.

Olson, M.J., and Budescu, D.V. (1997). Patterns of preference for numerical and verbal probabilities. Journal of Behavioral Decision Making, 10: 117-131.

Pownall, G., Wasley, C., and Waymire, G. (1993). Central and peripheral routes to advertising effectiveness: the moderating role of involvement. Journal of Consumer Research, 10: 135-156.

Reeder, G.D. and Brewer, M.B. (1979). Schematic model of dispositional attribution in interpersonal perception. Psychological Review, Vol. 86 (1): 61-79.

Rogers, J.L., and Stocken, P.C. (2005). Credibility of management forecasts. The Accounting Review, Vol. 80: 1233-1260.

Scheffé, H. (1959). The Analysis of Variance, New York: John Wiley \& Sons, Inc.

Spence, A.M. (1974). Market Signaling: Informational transfer in hiring and related screening processes. Cambridge: Harvard University Press.

Walsten, T.S., Budescu, D.V., Zwick, R., and Kemp, S.M. (1993). Preferences and reasons for communicating probabilistic information in verbal or numerical terms. Bulletin of the Psychonomic Society, 31: 135-138.

Williams, P.A. (1996). The relation between a prior earnings forecast by management and analyst response to a current management forecast. The Accounting Review, Vol. 71 (1): 103-113.

Windschitl, P.D. and Wells, G. (1996). Measuring psychological uncertainty: Verbal versus numeric. Journal of Experimental Psychology: Applied, 2: 343-364.

Zhang, X.F. (2006). Information uncertainty and analyst forecast behavior. Contemporary Accounting Research, Vol. 23 (2): 565-590.

Zimmer, A.C. (1983). Verbal vs. numerical processing of subjective probabilities, in Scholz, R.W. (ed.), Decision Making Under Uncertainty (pp. 377-98), New York: North-Holland.earnings guidance. Review of Accounting Studies, 10: 497-535. 